\title{
Rainfall Variability related to Global Climate Change: Its Effects on the Economic Activities in the North-Eastern Part of Nigeria
}

\author{
Manko Rose Rindap* \\ Department of Political Science, Plateau State University,P.M.B 2012, Bokkos, 932112, Plateau State, Nigeria
}

\begin{abstract}
This study analyses the impacts of rainfall variability caused by climate change in the north-eastern region of Nigeria. The study determined the trends and variation in rainfall at four stations for thirty years period, 1980-2009. Rainfall variability in the region was analysed in terms of spatial and temporal distribution. The study also examined the different sources of water, determined the changes in water availability from these sources, identify activities affected by climate change and determined adaptation strategies to cope with climate change. Secondary and primary (questionnaire survey of households in the area) data was used. A sample of 210 households from seven rural communities in North-eastern region of Nigeria was extracted from the data set for analysis. Both qualitative and quantitative statistical techniques were used to present and analysed the data respectively. The results revealed that rainfall variability have occurred in north-eastern region of Nigeria during the study period, exhibiting significant spatial and temporal variations. A drought occurred in the region when the annual rainfall is less than $85 \%$ of the long term mean. In conclusion, in order to adapt to rainfall variability, farmers adopted high yield varieties and crop and livestock diversifications.
\end{abstract}

Keywords: Climate Change, Water, Environment, Variability

\section{Introduction}

Recent growth in the world economy is even more remarkable. During the last half of the twentieth century, the world economy expanded sevenfold. Most striking of all, the growth in the world economy during the single year of 2000 exceeded that of the entire nineteenth century. Economic growth, now the goal of governments everywhere, has become the status quo. Stability is considered a departure from the norm. As the economy grows, its demands are outgrowing the earth, exceeding many of the planets natural capacities. Water use tripled, but the capacity of the hydrological system to produce fresh water through evaporation change little (Lester, 2004). This is why water tables are now falling in countries that contain more than half the world's people. While there is a broad replication that are facing a future of water shortages, not everyone has connected the dots to see that a future of water shortages will be a future of food shortages (Dimento and Doughman, 2007).Also, as global temperatures rise, rainfall will decline in already dry areas such as the air and semi-arid Sahel. Africa is thus particularly vulnerable to global warning because of its heavy dependence on rainfall agriculture. Global warning will reduce water availability for agriculture, affecting both crop yields and the carrying capacity of land in respect of livestock (Devereux, 2001).

Over the course of the twentieth century, decreasing rainfall in the semi-arid region has pushed northern pastoralists southwards into land occupied by sedentary farmers, leading to conflicts and widespread destruction of farmland and cattle. Meanwhile, to meet the growing needs for food, farmers are expanding into marginal lands traditionally used by pastoralists, heightening competition between livestock and agricultural production (Nyong, 2007). The livelihoods of dry-land producers who lack access to irrigation are particularly sensitive to fluctuations in precipitation (Kurukulasuriya and Mendelsohn, 2007).In addition to high inter-annual variability, the rainfall regime of the north-eastern Nigeria is characterized by high concentration in few months usually from August-September, which is not only intermittent but with storms. Thus, the region is prone to recurrent and sometimes intense period of drought especially within Borno and 
Yobe states which share a common boundary with the Sahara desert in the extreme end of Nigeria.It is on this background that the study looked at the rainfall variability and its effect on the economic activities in the North-eastern region of Nigeria.

\section{Statement of the Problem}

Rainfall in the north-eastern part of Nigeria has been fluctuating over the specified study period. The data gotten from the Nigerian Meteorological Agency showed that analysis of rainfall data (1980-2009) revealed that there had been high and reduced annual amount of rain in the study areas. For instance, Potiskum had the highest amount of rainfall of $967.1 \mathrm{~mm}$ in 1988 while the lowest amount of $368.5 \mathrm{~mm}$ was recorded in 1987. The concern is likely to affect the agricultural sector because over $80 \%$ of Nigerians' depend on rain-fed agriculture.

\section{Objectives of the Study}

To examine rainfall variability in the region over the years of study

To identify and examine activities affected by these changes.

To determine the adaptation strategies the people have used to cope with water scarcity and climate change.

\section{The Study Area}

The study area is the North-eastern region of Nigeria. It covers part of Bauchi, Borno and Yobe States and is a futureless plain, gently sloping east and north-eastward toward lake Chad. The many rivers and streams that flow through the study area are seasonal. Most of them on the way to Lake Chad flow into marshy areas and disappear by evapotranspiration before searching the lake. The area is the home land of the Kanuris' the Shuwars' and fulanis'.

\section{Climate of the Study Area}

The climate of the area is hot, semi-arid and like the rest of Nigeria, dominated by two main air masses. This brings with them the rain bearing south western winds, and the cold dry and dusty northeastern winds, locally known as the harmattan. At different times of the year, one or the other of the winds prevail and the area experiences either rainfall or the dry harmattan depending on the advance or retreat of the other yearly extremes in temperature range from 150c during the harmattan months to 40oc during the months of April and May. Evaporation rates are very high, particularly during the dry, hot season. The wet season last about three months and annual rainfall averages about $600 \mathrm{~mm}$.

\section{Method of Data Collection}

\section{Types and Sources of Data}

The secondary data was drawn strictly from the Nigerian Meteorological Agency, for the rainfall data for 30 years 1980-2009 and the Assessment of Impacts and Adaptations to Climate Change (AIACC) project conducted in Northern Nigeria by the Center for Environmental Resource and Hazards Research in the Department of Geography and Planning, University of Jos.

\section{Sample and Sampling Technique}

This research was an offshoot of the AIACC project conducted in Northern Nigeria by the Center for Environmental Research and Hazard Research in the Department of Geography and Planning, University of 
Jos. The questionnaire was the major tool for data collection. Systematic random sampling technique was used to select communities and households included in the survey. A total of 7 rural communities across the North-eastern region of Nigeria were selected for the survey. Copies of the questionnaire were then administered to 30 households in each of the selected communities given a total of 210 responses. The selected communities include: Badrama, Buniyadi, Chigowa, Damask, Kubani, Madara and Maimallamari. Through retrospective questioning, information on sources of water was as it helped us to determine the main surface of water and observed changes in water availability from water sources. Information on drought was useful as it told us which activities were affected most by water scarcity and climate change. Information on adaptation gave strategies for adaptation.

\section{Techniques for Data Analysis}

The descriptive statistical technique was used for the study. The descriptive statistics included data summaries in form of frequencies and percentages presented in tables.

\section{Results and Discussion}

The result showed that the North-eastern region of Nigeria generally experienced fluctuations in rainfall during the period of study (1980-2009), with the highest amount of 3438.6mm experienced in 1999 and the lowest amount of $1729.6 \mathrm{~mm}$ experienced in 1987 . The study period began with a wet phase of $2630.2 \mathrm{~mm}$, which lasted to 1981. A dry phase started in 1982 and lasted for three years. In 1986, another wet period was experienced followed by another dry periods in 1987, which interrupted the wet period from 1986-1989. After a dry spell in the 1990, the region continues to experience a wet phase up to 2009. Table 1 depicts the situations at the various stations.

Table 1: Total Annual Rainfall (in mm) for Four Stations in North-eastern Region of Nigeria (1980-2009)

\begin{tabular}{llllll}
\multicolumn{5}{c}{ STATIONS } & \\
Year & Potiskum & Nguru & Maiduguri & Bauchi & Total \\
1980 & 682.1 & 339.6 & 621.3 & 988.2 & 2630.2 \\
1981 & 733.5 & 428.9 & 461.4 & 1250.8 & 2874.6 \\
1982 & 575.3 & 409.3 & 355.9 & 897.1 & 2237.6 \\
1983 & 524.7 & 236.7 & 263.5 & 773.3 & 1798.2 \\
1984 & 462.3 & 332.4 & 348.1 & 893.7 & 2036.5 \\
1985 & 543.5 & 419.2 & 414.1 & 725.6 & 2102.4 \\
1986 & 810.4 & 240.6 & 509.5 & 946.1 & 2506.6 \\
1987 & 368.5 & 250.2 & 366.3 & 744.6 & 1729.6 \\
1988 & 967.1 & 320.6 & 622.8 & 920.7 & 2831.2 \\
1989 & 784.3 & 338.6 & 610.3 & 909.4 & 2642.6 \\
1990 & 410.5 & 418 & 426.5 & 879.6 & 2134.6 \\
1991 & 676.2 & 333.9 & 486.1 & 949.6 & 2445.8 \\
1992 & 624.6 & 415.1 & 584.6 & 1230.4 & 2854.7 \\
1993 & 556.8 & 298.3 & 490.7 & 1141.9 & 2487.7 \\
1994 & 785.2 & 491.4 & 317.1 & 1121.1 & 2714.8 \\
1995 & 568.5 & 383.3 & 630.6 & 961.4 & 2633.8 \\
1996 & 747.5 & 358.2 & 630.5 & 1140.6 & 2876.8 \\
1997 & 697.6 & 548.3 & 549.7 & 896.7 & 2692.3 \\
1998 & 820.8 & 467 & 692.2 & 1122.6 & 3102.6 \\
1999 & 746.5 & 446.8 & 844.6 & 1400.7 & 3438.6 \\
2000 & 593.8 & 355.6 & 677.4 & 1247 & 2873.8
\end{tabular}




$\begin{array}{llllll}2001 & 777.3 & 416 & 770.3 & 1318.2 & 3281.6 \\ 2002 & 669.2 & 442.9 & 368.3 & 819.1 & 2299.5 \\ 2003 & 703 & 450.3 & 653.3 & 989.5 & 2796.1 \\ 2004 & 616.9 & 293.5 & 616.1 & 865.5 & 2392 \\ 2005 & 683.9 & 501.7 & 901.9 & 1047.3 & 3134.8 \\ 2006 & 648.9 & 407.9 & 519.5 & 949 & 2524.9 \\ 2007 & 563.7 & 487.6 & 1076.3 & 1136.9 & 3264.5 \\ 2008 & 694.1 & 338.9 & 622.9 & 1133.1 & 2789 \\ 2009 & 676.1 & 366.5 & 694.1 & 1531.3 & 3168\end{array}$

\section{Spatial Variability of Rainfall in Northeastern Region of Nigeria}

To assess the variability in the rainfall distribution within the study area during the study period, table 1 above has been used in the study and for the entire study area during the 30 years study period to assess the spatial variability of rainfall.The standard deviations and coefficients of variability were calculated on annual bases. From the table below, it can be observed in Table 2:

Table 2: Total, Mean values, Standard Deviation and Coefficient of Variation for Annual Rainfall (mm) for four stations in North Eastern Region of Nigeria.

\begin{tabular}{|lllll|}
\hline Stations & Postiskum & Nguru & Maiduguri & Bauchi \\
\hline Total & 19712.4 & 11537.3 & 17125.9 & 30931 \\
Mean & 657.08 & 384.58 & 570.86 & 192.75 \\
Standard & 125.87 & 77.92 & 179.08 & 192.75 \\
Coefficient of Variation & 19.16 & 20.26 & 31.37 & 18.69 \\
\hline
\end{tabular}

Source: Author's Analysis

From the analysis, Bauchi recorded the highest annual standard deputation of 192.75 while Nguru experienced the least value of 77.92. The coefficient of variation which expresses the relative deputation in rainfall amount, are also presented in the table above. During the thirty year period of study, Bauchi has the least coefficient of variation in rainfall of $18.69 \%$ followed by Potiskum with $19.16 \%$, Nguru $20.26 \%$ and Maiduguri with $31.37 \%$. From the results of these analyses, it is suggested that spatial variations in rainfall in the study area are attributed to the total amount of rainfall received at each location where the annual rainfall was low, the coefficient of variation was high and vice-versa.

The following section will reveal the perception of respondent for the past 10 years (1992-2003).

Table 3: Perception of Drought Responses

\begin{tabular}{|lcccc|}
\hline What is drought & Frequency & Percentage \\
\hline Lack of rain in rainy season & 93 & & 48.4 & \\
Insufficient rainfall after planting & 38 & & 19.8 & \\
Absence or shortage rain & & 32 & & 16.7 \\
Dryness due to lack or shortage of rain & 9 & & 4.7 & \\
When your crops dries up or not producing anything & 20 & & 10.4 \\
Total & 192 & & 100 & \\
\hline
\end{tabular}


Source: AICC-AF; 92, Data Base summarized by author, 2020

From the trends of rainfall in the four stations used for the study, a number of drought periods were discovered and presented in table 1 and 2 . This is in line with the perception of the respondents on drought for the past 10 years (1999-2003) when the questionnaire for rural households and droughts in theSahel region of West Africa; Vulnerability and Effective Adaptation Measures (AIACC-FC: 92) data was collected.

Table 4: Sources of water in North-eastern Region of Nigeria

\begin{tabular}{|llc|}
\hline Water sources & Frequency & Percentage \\
\hline Rain & 98 & 27.8 \\
Pond & 3 & 0.9 \\
River & 2 & 0.6 \\
Well & 149 & 42.3 \\
Boreholes & 55 & 15.6 \\
Pipe & 45 & 12.8 \\
Total & 352 & 100 \\
\hline
\end{tabular}

The response showed that the major source of water is the well, which can be seen by the responses. $42.3 \%$ of the respondent affirmed to this.

Furthermore, observed changes in rainfall under these conditions were asked (total amount, time of onset, time of cessation, frequency of rain events and intensity of rain events), Ground water under the following conditions (level of water table, timing of recharge (rise) and timing of discharge (fall) and stream flow with respect to the following conditions (level of stream flow, time of recharge, time of cessation and frequency of floods. The data obtained in the field are summarized and presented in table 5.

Table 5: Drought and Environmental concerns in the North-eastern region.

\begin{tabular}{|c|c|c|c|c|c|c|c|c|c|c|}
\hline \multicolumn{11}{|c|}{ Changes observed over the 10 years } \\
\hline \multicolumn{2}{|l|}{ Sources of Water } & \multicolumn{2}{|c|}{ Increase } & \multirow{2}{*}{$\%$} & \multicolumn{2}{|c|}{ Decrease } & \multirow{2}{*}{$\%$} & \multicolumn{2}{|c|}{ No changes } & \multirow[t]{2}{*}{$\%$} \\
\hline \multicolumn{8}{|l|}{ Rainfall } & & & \\
\hline Total Amount & 86 & & 43.2 & 86 & & 44.7 & 24 & & 12.1 & \\
\hline Time on set & 49 & & 24.6 & 99 & & 49.7 & 51 & & 25.6 & \\
\hline Time of cessation & & 43 & & 21.6 & 126 & & 63.3 & 30 & & 15.1 \\
\hline Frequency of rain events & & 59 & & 29.6 & 111 & & 55.8 & 29 & & 14.6 \\
\hline Intensity of rain events 4 & 42 & & 21.1 & 127 & & 63.8 & 30 & & 15.1 & \\
\hline \multicolumn{11}{|l|}{ Ground water } \\
\hline Level of water table & 45 & & 22.6 & 89 & & 44.7 & 65 & & 32.7 & \\
\hline Timing of recharge (rise) & & 66 & & 32.2 & 96 & & 48.2 & 37 & & 18.6 \\
\hline Timing of discharge (fall) & & 41 & & 20.6 & 100 & & 50.3 & 58 & & 26.1 \\
\hline \multicolumn{11}{|l|}{ Stream flows } \\
\hline Level of stream flows 4 & 45 & & 22.6 & 86 & & 43.2 & 68 & & 34.2 & \\
\hline
\end{tabular}




\begin{tabular}{|c|c|c|c|c|c|c|c|c|c|}
\hline Time of recharge & & 35 & & 17.6 & 99 & & 49.7 & 65 & 32.7 \\
\hline Time of cessation & & 29 & & 14.6 & 109 & & 54.8 & 61 & 30.7 \\
\hline Frequency of floods & 36 & & 18.1 & 82 & & 41.2 & 81 & & 40.7 \\
\hline
\end{tabular}

Source: AIACC-AF; 92, Data Base Summarized by the author, 2020

From the above table, the data revealed that the general amount of rainfall in the study area has decreased along with the time of commencement by $44.7 \%$ and $49.7 \%$ respectively. The period, in which it normally stopped to mark the commencement of the dry season, the frequency of the rainfall events and its intensity has also decrease over the years by $63.3 \%, 55.8 \%$ and $63.8 \%$ respectively in the study area. The ground water table level, its recharge and discharge decreased by $44.7 \%, 48.2 \%$ and $50.3 \%$. This can be attributed to the fact that the principal source of natural recharge for ground water is rainfall. This is because decrease in total amount of rainfall has led to decrease in groundwater recharge.

\section{Adaptation Strategies Adopted by People in the North East to Respond to Rainfall Variability}

From the analysis of the survey data, a number of coping strategies have been identified. The coping strategy is divided into two categories, past and present. Past coping strategies are strategies adopted by the respondents during droughts that occurred in 1994 or earlier, while present coping strategies are more recent strategies adopted by the respondents after 1994.

Table 6: Respondents Coping and Adaptation Strategies

\begin{tabular}{|c|c|c|c|c|c|c|c|c|}
\hline \multicolumn{2}{|l|}{ Strategy } & \multirow{2}{*}{$\begin{array}{l}\text { Past } \\
61\end{array}$} & \multirow{2}{*}{$\begin{array}{l}\% \\
54\end{array}$} & \multicolumn{2}{|c|}{ Present } & \multicolumn{2}{|l|}{$\%$} & \multirow{3}{*}{$\begin{array}{l}\text { Total } \\
113\end{array}$} \\
\hline Drought resistant variet & & & & 52 & & 46 & & \\
\hline Crop diversification & 47 & 38.2 & 76 & & 61.8 & & 123 & \\
\hline Livestock diversificatio & & 60 & 57.1 & 45 & & 42.9 & & 105 \\
\hline Early matured crop vari & eties43 & 29.3 & 104 & & 70.7 & & 147 & \\
\hline High yield varieties & 38 & 25.3 & 112 & & 74.7 & & 150 & \\
\hline Low input varieties & 41 & 42.3 & 56 & & 57.7 & & 97 & \\
\hline Irrigated crops & 27 & 64.3 & 15 & & 35.7 & & 42 & \\
\hline Replanting & 83 & 72.2 & 32 & & 27.8 & & 115 & \\
\hline Herd movement & 25 & 54.3 & 21 & & 45.7 & & 46 & \\
\hline Herd supplementation & 23 & 41.8 & 32 & & 58.2 & & 55 & \\
\hline Culling animals & 18 & 41.9 & 25 & & 58.1 & & 43 & \\
\hline Labour migration & & 29 & 59.2 & 20 & & 40.8 & & 49 \\
\hline Selling assets & 71 & 70.3 & 30 & & 29.7 & & 101 & \\
\hline Herds sedentarization & 40 & 63.5 & 23 & & 36.5 & & 63 & \\
\hline Farm relocation & 74 & 74 & 26 & & 26 & & 100 & \\
\hline Herd/farm sizes & 35 & 53.8 & 30 & & 46.2 & & 65 & \\
\hline Water exploitation meth & od & 33 & 60 & 22 & & 40 & & 55 \\
\hline Water use & 69 & 78.4 & 19 & & 21.6 & & 88 & \\
\hline Water storage methods & 49 & 57.6 & 36 & & 42.4 & & 85 & \\
\hline Food storage & 118 & 78.1 & 33 & & 21.9 & & 151 & \\
\hline
\end{tabular}

Source: AIACC-AF: 92, Data Base Summarized by Author, 2020 
Food storage was the coping strategy adopted by the largest number of the respondents in the past, followed by replanting of crops when they are lost; farm relocation; selling of assets; varieties of strategies for water use; cultivation of drought resistant varieties and livestock diversification. Recently, the number of people using food storage, replanting of crops when they are lost and farm relocation have declined from $78.1 \%$ to $21.9 \%, 72.2 \%$ to $27.8 \%$ to $26 \%$ respectively. Other strategies that have declined in use are selling of assets, varieties of strategies for water use, cultivation of drought resistant varieties and livestock diversification. These strategies have declined from $70.3 \%$ to $29.7 \%, 69 \%$ to $21.6 \%, 54 \%$ to $46 \%$ and from $57.1 \%$ to $42.9 \%$ respectively. Nonetheless, some coping strategies have increased in use, most notably, adoption of high yield varieties, early mature crop varieties and crop diversification. These strategies have increased from $25.3 \%$ to $74.7 \%, 29.3 \%$ to $70.7 \%$ and from $38.2 \%$ to $61.8 \%$ respectively. Others are low input varieties from $42.3 \%$ to $57.7 \%$, herd supplementation, from $41.8 \%$ to $58.2 \%$ and culling animals from $41.9 \%$ to $58.1 \%$.

\section{Conclusion}

As it was observed, there was a significant variation in climate in rainfall. This is because, the research revealed that there was an all-round decrease in the total amount of rainfall, time of on-set, time of cessation, frequency of rain events and intensity of rain events. The above indication showed the changes in the climate of the north-eastern region of Nigeria. We were able to discover periods of wet phase always alternating with dry spell periods. Coping and adaptation strategies presently used (high yield varieties, culling animals planting crops when they are lost, crop and livestock diversifications etc) were also discovered. The variation in rainfall in the four stations used in the study area and the water sources, the decreased observed in rainfall, groundwater and streams flows were indications of climate change and its adverse impact on the economic activities of the people in the North-eastern region of Nigeria.

\section{References}

Dimento, J.F.C.,\& Doughman, P. (2007).Climate change: What it means for us, our children and our grandchildren. Massachusetts: Massachusetts Institute of Technology (M.I.T) Press.

Devereux, S. (2001).Famine in Africa. In S. Devereux \& S. Maxwell (Eds.), Food Security in Sub-Saharan Africa (pp.199-147). Britain: Intermediate Technology Development Group (I.T.D.G) Press.

Kurukulasuriya, P., \& Mandelsohn, R.O. (2007).A Ricardian Analysis of the Impact of Climate Change on African Cropland (No. 4305). Washington: World Bank Policy Research World Paper.

Lester, B. (2004).Outgrowing the earth: The food security challenges in an age of falling water tables and rising temperatures. New York: W.N Norton \& Company Press.

Nyong, A. (2007). Climate-related conflicts in West Africa: Environmental Change and Security Program (Rep. No. 12). Washington: Woodrow Wilson International Centre for Scholars. 